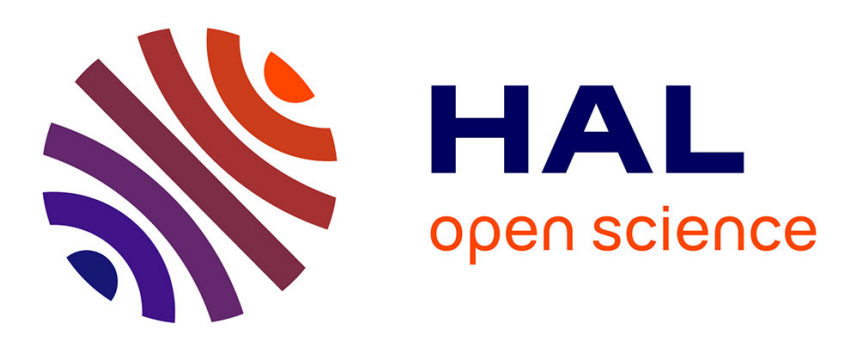

\title{
Preparation of polyurethane microspheres dispersed in an epoxy prepolymer
}

\author{
Abderrahim Djahieche, Françoise Méchin, Jean Pierre Pascault
}

\section{To cite this version:}

Abderrahim Djahieche, Françoise Méchin, Jean Pierre Pascault. Preparation of polyurethane microspheres dispersed in an epoxy prepolymer. Macromolecular Symposia, 2000, 151 (1), pp.353-358. 10.1002/1521-3900(200002)151:13.0.CO;2-4 . hal-02045906

\section{HAL Id: hal-02045906 https://hal.science/hal-02045906}

Submitted on 23 Jul 2019

HAL is a multi-disciplinary open access archive for the deposit and dissemination of scientific research documents, whether they are published or not. The documents may come from teaching and research institutions in France or abroad, or from public or private research centers.
L'archive ouverte pluridisciplinaire HAL, est destinée au dépôt et à la diffusion de documents scientifiques de niveau recherche, publiés ou non, émanant des établissements d'enseignement et de recherche français ou étrangers, des laboratoires publics ou privés. 


\title{
PREPARATION OF POLYURETHANE MICROSPHERES DISPERSED IN AN EPOXY PREPOLYMER
}

\author{
Abderrahim Djahieche, Françoise Méchin*, Jean Pierre Pascault \\ Laboratoire des Matériaux Macromoléculaires, UMR CNRS n5627 \\ Institut National des Sciences Appliquées de Lyon, Bât. 403 \\ 20, avenue Albert Einstein - 69621 Villeurbanne Cedex, France
}

SUMMARY: Hydroxy-terminated polybutadiene (HTPB) was dispersed into a continuous phase of diglycidyl ether of bisphenol A (DGEBA) as droplets of $2 \mu \mathrm{m}$ average diameter. 4,4'-diisocyanato dicyclohexyl methane $\left(\mathrm{H}_{12} \mathrm{MDI}\right)$ was introduced to react with the dispersed phase via interfacial polycondensation. The reaction kinetics was studied at various temperatures and compared to that of homogeneous $\mathrm{HTPB} / \mathrm{H}_{12} \mathrm{MDI}$ systems. Diisocyanate partition coefficient has been determined on a non-reactive dispersion prepared after neutralisation of hydroxyl groups of each phase, with p-tolylisocyanate (pTI). Results shows that $28 \%$ of the introduced $\mathrm{H}_{12} \mathrm{MDI}$ would be present in the polybutadiene phase; further interfacial reaction leads to crosslinked polyurethane particles.

\section{Introduction}

Polyepoxide networks derived from the polycondensation of a diepoxide prepolymer with a diamine are usually very brittle. They are thus often toughened ${ }^{1)}$ by incorporating into the starting reactive mixture a thermoplastic or elastomeric additive, which generally phaseseparates during the reaction and leads to dispersed reinforcing nodules. Their morphology strongly depends on initial component miscibility, temperature, reaction kinetics, and viscosity, and is thus sometimes difficult to control. An alternative solution can be found in dispersing preformed particles (e.g. core-shell type elastomer particles ${ }^{2,3}$, or thermoplastic microspheres); in this way the morphology and size distribution of the dispersed phase can be designed and fixed from the start. In this work, we present an attempt to prepare the preformed particles in situ in the epoxy prepolymer through the crosslinking of reactive elastomer droplets by interfacial polycondensation.

\section{Dispersion of elastomer into diepoxide continuous phase}

A liquid polyfunctional $\left(\overline{\mathrm{f}_{\mathrm{n}}} \approx 2.5\right)$ polyol, based on hydroxyl-terminated polybutadiene supplied by Elf-Atochem (R45HT / $\overline{\mathrm{M}_{\mathrm{n}}}=2830 \mathrm{~g} \cdot \mathrm{mol}^{-1}$ ) was dispersed in a continuous phase of diglycidyl ether of bisphenol A (DGEBA / $\mathrm{M}=380$ g.mol ${ }^{-1}$ ). Non-miscibility of these two 
components was observed, consistently with what the solubility parameters (calculated by Smalls' group contribution method ${ }^{4)}$ ) suggested. The values obtained are presented in Table 1.

Table 1. Solubility parameters of the dispersion components

\begin{tabular}{cc}
\hline Components & $\delta$ \\
\cline { 2 - 2 } & $\left(\mathrm{cal} / \mathrm{cm}^{3}\right)^{1 / 2}$ \\
\hline DGEBA $(\mathrm{n}=0.15)$ & 10.6 \\
HTPB & 8.0 \\
\hline
\end{tabular}

The difference in solubility parameters is greater than $0.2\left(\mathrm{cal} / \mathrm{cm}^{3}\right)^{1 / 2}$, so the usual empirical non-miscibility criterion is respected.

The elastomeric polyol was dispersed into DGEBA (10\% v/v) by stirring (10000 rpm, UltraTurrax type laboratory homogeniser) for 10 minutes. The method of assessment of droplets diameters was optical microscopy after dilution (1/9 v/v) into pure DGEBA, to minimise coalescence. A typical droplet diameter distribution is shown in Figure 1.

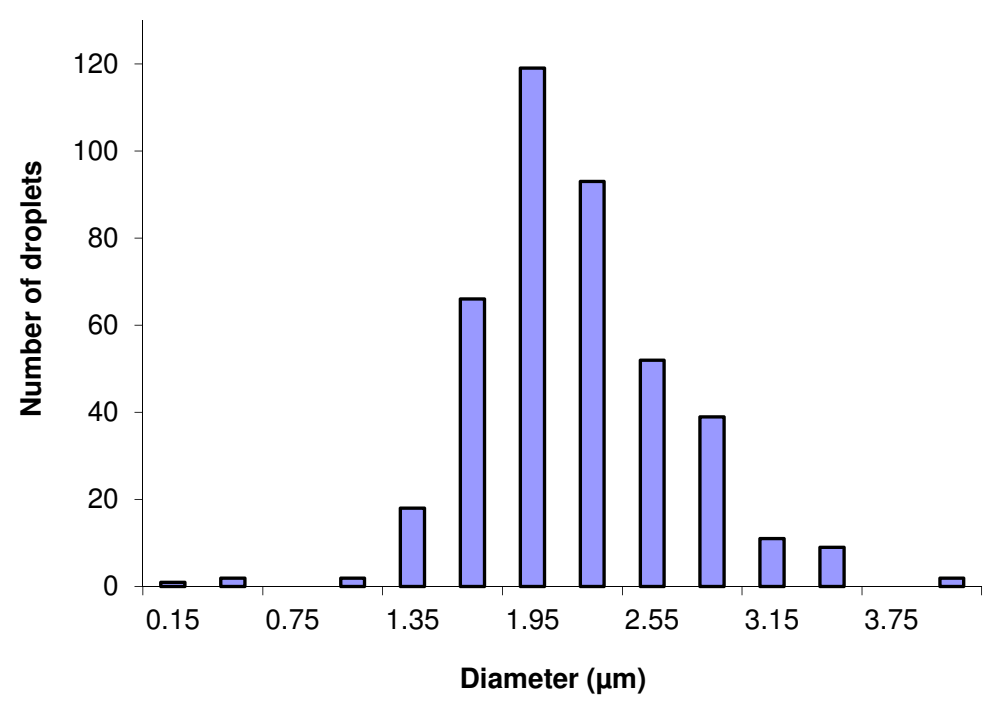

Fig.1: Polyol droplet size distribution in DGEBA continuous phase

When dispersions were observed without previous dilution, they displayed maximum coalescence droplet size of nearly $10 \mu \mathrm{m}$. Despite this, we observed a remarkable long-term stability at room temperature. Moreover, partial miscibility with a slight diffusion of DGEBA in the interface vicinity was observed at higher temperature (typically $85^{\circ} \mathrm{C}$, i.e. the temperature used for crosslinking reactions), see Figure 2. A distance of diffusion, measured as limit of appearance of a dispersed phase, was estimated at $0.9 \mathrm{~mm}$ after 10 hours at $85^{\circ} \mathrm{C}$. 


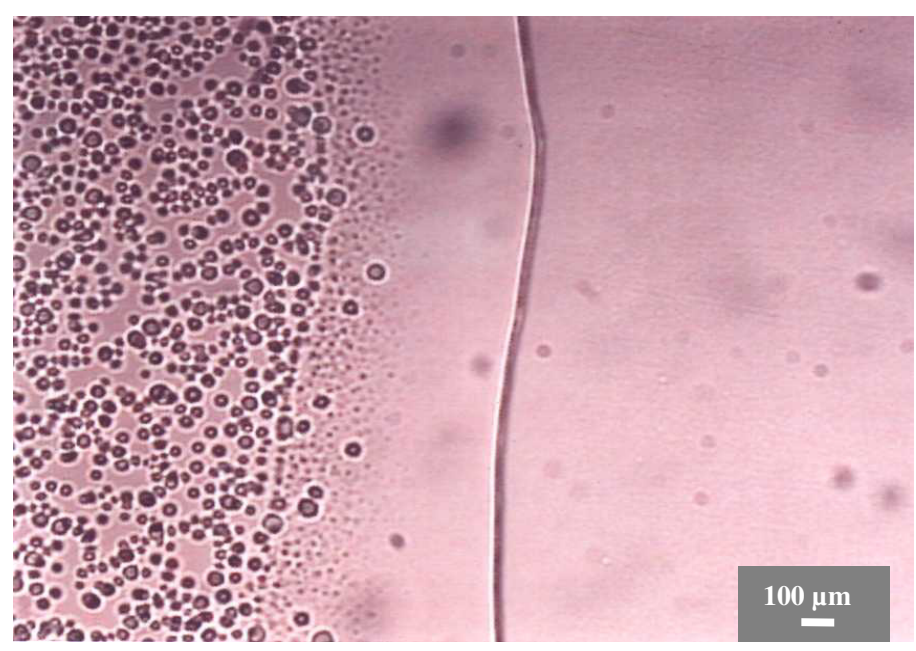

Fig. 2: Observation, at $25^{\circ} \mathrm{C}$, of a linear interface of HTPB/DGEBA system (After 10 hours at $85^{\circ} \mathrm{C}$ )

\section{Kinetic study of homogeneous reaction}

A medium-reactivity diisocyanate, 4,4'-diisocyanato dicyclohexyl methane $\left(\mathrm{H}_{12} \mathrm{MDI}\right)$ was chosen for the crosslinking of the dispersed hydroxyl-functional elastomer droplets. The reaction kinetics was at first studied on homogeneous $\mathrm{R} 45 \mathrm{HT} / \mathrm{H}_{12} \mathrm{MDI}$ systems at various temperatures.

Isocyanate conversion (estimated by the ratio $[\mathrm{NCO}] /[\mathrm{NCO}]_{0}$ ) was monitored by FTIR; the reaction was run in situ between $\mathrm{KBr}$ pellets in a heating cell. Spectra were collected at regular intervals. The reaction was found to follow second-order kinetics up to high conversions, eq.(1).

$$
-\frac{d[N C O]}{d t}=K_{2}[N C O][O H]
$$

Integration of eq.(1) and fitting of the experimental data leads to the following values:

Table 2. Second order rate constants of homogeneous $\mathrm{HTPB} / \mathrm{H}_{12} \mathrm{MDI}$ reaction

\begin{tabular}{|c|c|c|c|c|c|}
\hline Temperature $\left({ }^{\circ} \mathrm{C}\right)$ & 70 & 80 & 90 & 100 & 111.6 \\
\hline $\mathrm{K}_{2} \quad \mathrm{l} /(\mathrm{mol} \bullet \mathrm{h})$ & 0.22 & 0.33 & 0.58 & 1.12 & 2.02 \\
\hline
\end{tabular}

These rate constants follow the Arrhenius law, with a calculated activation energy of $57 \mathrm{~kJ} \bullet \mathrm{mol}^{-1}$. As we were interested in crosslinking HTPB droplets, rheological techniques have been used to determine the gelation time. The viscosity of the reacting mixture was followed in a CONTRAVES Rheomat 115, Couette type, viscosimeter. Dynamic mechanical analysis was used too; typically a $1 \mathrm{~mm}$ thick liquid mixture was placed between two parallel circular plates of a RHEOMETRICS RDA 700, and examined in a frequency sweep mode. 
The DGEBA used in this work (LY 556, supplied by Ciba-Geigy) contains some molecules (15\%) bearing one hydroxyl function. To avoid reaction during kinetic studies, these functions were neutralised with p-tolylisocyanate (pTI) in a first step.

For diisocyanate partition coefficient determination, we prepared a special dispersion after neutralisation of the hydroxyl groups of each phase with stoichiometric amounts of pTI.

The reaction of $\mathrm{H}_{12} \mathrm{MDI}$ with the continuous phase was also investigated. Although DGEBA bears only few secondary hydroxyl groups, their number represents 6 times that of the polyol phase. In contrast, epoxy functions are perfectly stable under our experimental conditions. Figure 3 shows a stoichiometric $\mathrm{H}_{12} \mathrm{MDI} / \mathrm{DGEBA}$ reaction kinetics at $85^{\circ} \mathrm{C}$.

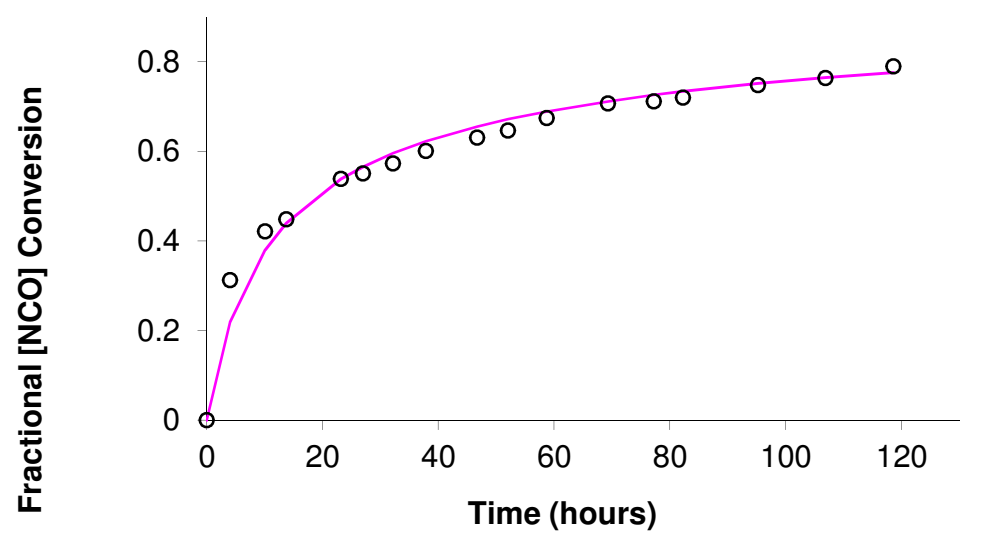

Fig. 3: Simulation of $\mathrm{H}_{12} \mathrm{MDI} / \mathrm{DGEBA}$ reaction kinetics at $85^{\circ} \mathrm{C}$ by a third order model

\section{Model membrane growth}

In order to simulate the microsphere crosslinking, an appropriate amount of $\mathrm{H}_{12} \mathrm{MDI}$ was dissolved in "neutralised" DGEBA-pTI. This first phase was placed in a test tube and pure HTPB (of lower specific weight) was then poured on top of it (initial $\mathrm{NCO} / \mathrm{OH}=2$ ).

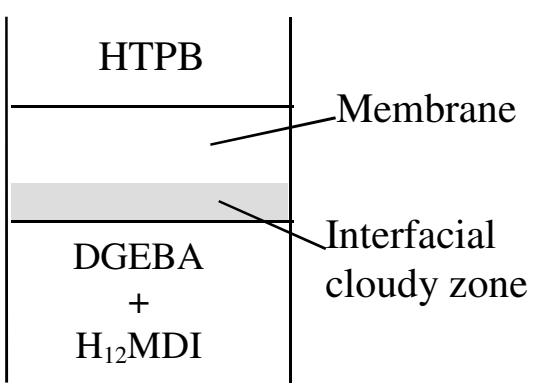

Fig. 4: Model membrane experiment

The interface soon became fuzzy, and a continuous growth of a polymer membrane was observed inside the polybutadiene phase, leading to a thick crosslinked material. This experiment revealed that the initial membrane was permeable enough to ensure $\mathrm{H}_{12} \mathrm{MDI}$ diffusion, and was thus very promising for the dispersion, which in comparison would display a huge interfacial area. 


\section{Preparation of in situ crosslinked dispersions}

The diisocyanate was at first added to a totally non-reactive dispersion based on DGEBA-pTI and R45HT-pTI. In this way, it was possible to estimate a partition coefficient for this reagent: a value very close to 5 was found for the ratio $\left[\mathrm{H}_{12} \mathrm{MDI}\right]_{\mathrm{R} 45 \mathrm{HT}-\mathrm{pTI}} /\left[\mathrm{H}_{12} \mathrm{MDI}\right]_{\text {DGEBA-pTI}}$. Taking into account the actual volume fraction, this would mean that at equilibrium $\approx 28 \%$ of the total amount of $\mathrm{H}_{12} \mathrm{MDI}$ would initially be present in the polybutadiene phase. Finally, the diisocyanate was added to reactive dispersions and crosslinked particles could be obtained. The process kinetics was followed by FTIR as a function of temperature. Experimental data are presented in Figure 5.

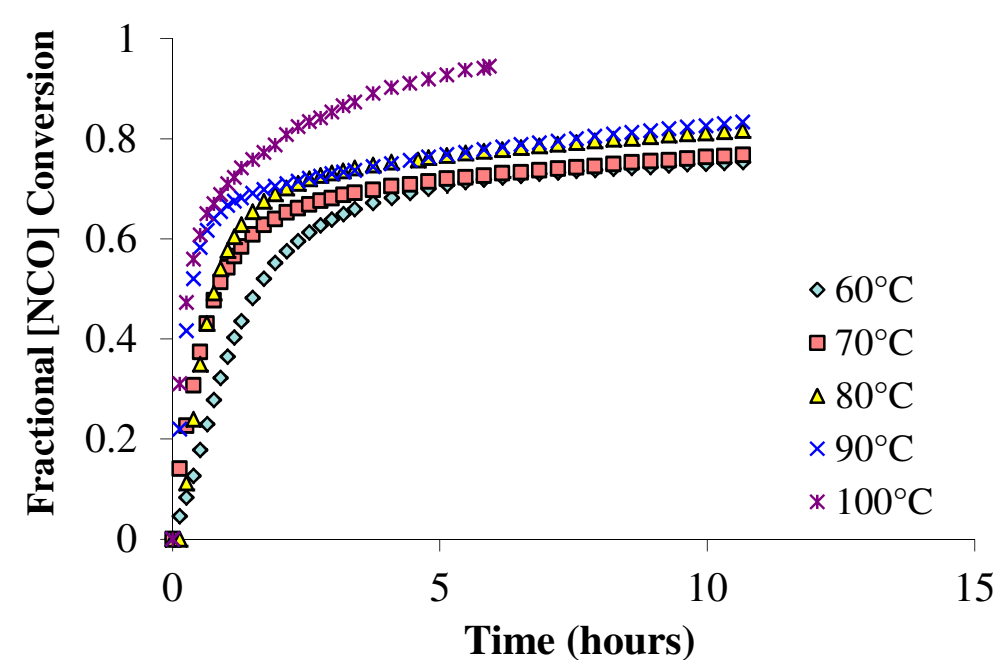

Fig. 5: Interfacial polycondensation kinetics of $\mathrm{H}_{12} \mathrm{MDI}$ with dispersed HTPB in neutralised DGEBA.

Attempts to model our results using Pearson's formalism ${ }^{6,7)}$ (established for a slightly different system) were unsuccessful. Collected kinetic data below $100^{\circ} \mathrm{C}$ have been well simulated by a second order model, with non-stoichiometric initial conditions ${ }^{8)}$, eq.(2). Second order kinetics was established for solvent diluted homogeneous systems. In our heterogeneous system DGEBA may act as a solvent. Hydroxyl groups located inside the droplets are isolated from dissolved isocyanate, so non-stoichiometric initial conditions may arise from this situation.

$$
-\frac{d[N C O]}{d t}=\frac{d[U]}{d t}=K\left([N C O]_{0}-[U]\right)\left([O H]_{0}-[U]\right)
$$

Integration of equation (2) gives

$$
\frac{1}{[O H]_{0}(1-r)} \ln \left(\frac{(1-r P)}{(1-P)}\right)=K t
$$

where $[\mathrm{U}]=$ urethane concentration, $\mathrm{r}=[\mathrm{NCO}]_{0} /[\mathrm{OH}]_{0}$, and $\mathrm{P}$ is the $\mathrm{NCO}$ conversion

The limiting effect of the diisocyanate diffusion through the polyurethane membrane seems to be more pronounced at $100^{\circ} \mathrm{C}$. The previous situation led us to suggest a model based on superficial hydroxyl group concentration, equation (4). 


$$
-\frac{d[\mathrm{NCO}]}{d t}=K_{D}[\mathrm{OH}]_{i}^{m}
$$

$$
\begin{aligned}
& {[\mathrm{OH}]_{i}=S_{i} / A_{O H} \quad \text { where } \quad S_{i}=\text { total interfacial surface }} \\
& S_{i}=n^{\prime}{ }_{v} 4 \pi r_{l}{ }^{2} \quad n_{v}^{\prime}=\text { number of droplets per unit volume } \\
& r_{1}=\text { liquid core radius of the reacting particle } \\
& r_{1}=r_{0}(1-P)^{1 / 3}
\end{aligned}
$$

On introducing these parameters, equation (4) may be simply written :

$$
\frac{d P}{d t}=K(1-P)^{n} \quad \text { where } K=\frac{K_{D} r_{0}^{2 m}}{[N C O]_{0}}\left[\frac{n^{\prime}{ }_{v} 4}{A_{O H}}\right]^{m}, \quad n=\frac{2 m}{3}
$$

Integration of equation (5) gives

$$
\frac{1}{n-1}\left[(1-P)^{1-n}-1\right]=K t
$$

During the first hour, experimental conversions are higher than simulated ones probably because our model does not take into account the diisocyanate initially present inside the HTPB droplets. Simulation of $100^{\circ} \mathrm{C}$ kinetics is well fitted after one hour reaction.

\section{Conclusions}

The observed second order reaction means that the interfacial $\mathrm{H}_{12} \mathrm{MDI} / \mathrm{HTPB}$ reaction in DGEBA proceeds like a solution reaction under $100^{\circ} \mathrm{C}$. This result is in good agreement with the small size of HTPB droplets and the observed DGEBA partial diffusion into this dispersed phase. Measurements of the thickness of the interfacial membrane in a non-dispersed system show that a shrinking core process is possible. The proposed shrinking core particle model, for high temperature heterogeneous reactions, fits our experimental results better than other models in the literature. However the model needs to be improved to take into account initially dissolved diisocyanate.

\section{References}

1. C. K. Riew, A. J. Kinloch, "Toughened Plastics II. Novel Approaches in Science and Engineering", Advances in Chemistry Series 252, ACS, Washington (1996), and references therein.

2. L. Bécu, H. Sautereau, A. Maazouz, J. F. Gérard, M. Pabon, C. Pichot, Polym. Adv. Technol. 6, 316 (1995).

3. L. Bécu, A. Maazouz, H. Sautereau, J.F. Gérard, J. Appl. Polym. Sci. 65, 2419 (1997).

4. M. M. Coleman, J. F. Graf, P. C. Painter, in: Specific interactions and the miscibility of polymer blends, Technomic Publishing Co. Inc., 1991, p. 55

5. H. Okada \& Y. Iwakura, Macromol. Chem.., 66, 91-101 (1963).

6. R.G. Pearson, E.L. Williams, J. Polym. Sci., Polym. Chem. Ed. 23, 9 (1985).

7. R.G. Pearson, E.L. Williams, J. Polym. Sci., Polym. Chem. Ed. 25, 565 (1987).

8. I. Yilgor, J. E. McGrath, J. Appl. Polym. Sci., 30, 1733, 1985. 